\title{
Managing anemia in patients with chronic heart failure: what do we know?
}

\author{
This article was published in the following Dove Press journal: \\ Vascular Health and Risk Management \\ 8 April 2010 \\ Number of times this article has been viewed
}

\author{
Ankur Sandhu' \\ Sandeep Soman' \\ Michael Hudson ${ }^{2}$ \\ Anatole Besarab' \\ 'Divisions of Nephrology, \\ ${ }^{2}$ Cardiology, Henry Ford Health \\ System, Detroit, Michigan, USA
}

Correspondence: Anatole Besarab Henry Ford Hospital, 2799 West Grand Blvd, Detroit, Ml 48202, USA

Email abesaral@hfhs.org

\begin{abstract}
Anemia is common in patients with chronic heart failure (HF) with an incidence ranging from $4 \%$ to $55 \%$ depending on the studied population. Several studies have highlighted that the prevalence of anemia increases with worsening heart failure as reflected by New York Heart Association classification. Additionally, several epidemiological studies have highlighted its role as a prognostic marker, linking it to worse outcomes including; malnutrition, increased hospitalizations, refractory heart failure and death. The pathophysiology of anemia is multifactorial and related to various factors including; hemodilution, iron losses from anti-platelet drugs, activation of the inflammatory cascade, urinary losses of erythropoietin and associated renal insufficiency. There are a host of epidemiological studies examining HF outcomes and anemia, but only a few randomized trials addressing this issue. The purpose of this article is to review the literature that examines the interrelationship of anemia and congestive HF, analyzing its etiology, impact on outcomes and also the role of associated kidney disease as well as cardiorenal syndrome both as a marker of morbidity and mortality.
\end{abstract}

Keywords: anemia, cardio-renal syndrome, heart failure

\section{Background}

In the US, heart failure (HF) is a leading cause of hospitalization with an estimated number of 900,000 hospitalizations per annum when HF is the primary diagnosis and 2.6 million when HF is the primary or secondary diagnosis. ${ }^{1}$ It is estimated that among these individuals, $4 \%$ to $61 \%$ have anemia and up to $33 \%$ have chronic kidney disease (CKD).$^{2-9}$ Variability in the estimated prevalence of anemia is partly attributable to use of different definitions of anemia in individual reports. Most of these patients are over 65 years of age, Medicare eligible, and place a huge economic burden on the health care system, with an estimated annual cost in the US of approximately $\$ 40$ billion. ${ }^{10,11}$

The annual mortality rate of patients suffering from congestive heart failure (CHF) refractory to standard medical treatment exceeds 50\%. ${ }^{12}$ Furthermore, deaths attributed to HF have increased $145 \%$ in the last 2 decades. ${ }^{13}$ This increased mortality, despite advances in medical treatment, points to the importance of identifying factors related to poor outcomes and developing new treatment and prevention modalities.

Coronary artery disease (CAD) and hypertension are the two major risk factors for the development of HF in older persons. Other common etiologies include diabetes mellitus, valvular heart disease - especially aortic stenosis and mitral regurgitation - and nonischemic cardiomyopathies. Frequently, HF in older persons is multifactorial. ${ }^{14}$

Older patients with hypertension and echocardiographic left ventricular (LV) hypertrophy had a 2.6-times higher incidence of HF than those with hypertension and 
no LV hypertrophy. LV hypertrophy by electrocardiography (ECG) and diabetes mellitus are also risk factors for the development of HF in older persons. ${ }^{14,15}$ In a 43-month follow up of 2902 patients ( 926 men and 1976 women) with a mean age of 81 years, HF developed in $27 \%$ of patients. Significant independent risk factors for the development of $\mathrm{HF}$ were male gender (risk ratio $=1.4$ ), hypertension (risk ratio $=2.5$ ), CAD $($ risk ratio $=4.0)$, diabetes mellitus (risk ratio $=1.6$ ), and age $\left(\right.$ risk ratio $=1.05$ for each yearly increase in age). ${ }^{14,16}$

\section{Anemia, HF and kidney function}

In a meta-analysis of 16 studies, Smith et $\mathrm{al}^{2}$ found that $63 \%$ of 80,098 patients with HF had some degree of concomitant impaired renal function, and $29 \%$ had severe CKD. This is of great clinical relevance because it is well known that renal dysfunction in patients with $\mathrm{HF}$ is associated with an increased risk of adverse outcomes. ${ }^{2,17}$

In a study by Hillege et al impaired renal function was found to be an even stronger predictor of mortality than ejection fraction (EF) or New York Heart Association (NYHA) functional class in 1906 patients with HF. ${ }^{9}$ The reciprocal relationship also holds true and has been the subject of much interest. Cardiovascular disease (CVD) is a very common comorbidity in patients with CKD or end stage renal disease (ESRD)and is the leading cause of mortality in this patient population. Indeed, HF is the key component of cardiovascular (CV) morbidity and mortality across the entire spectrum of CKD, with a 2-year cumulative probability of $39.5 \% .^{18}$ In a study of the Medicare population, Foley et al found that $39.9 \%$ of patients with CKD also had HF on initial presentation, and another $30.7 \%$ developed it over the following year. ${ }^{19}$ Not only is HF the most common type of CV disease seen in patients new to ESRD, but according to the US Renal Data System 2007 annual data report, approximately two-thirds of incident dialysis patients develop HF within 3 years. ${ }^{18}$

Not surprisingly, CVD is the leading cause of morbidity and mortality in dialysis patients, afflicting more than $50 \%$ of this population. As much as $64 \%$ of the ESRD population, who are dialysis dependent, have chronic HF, further highlighting the bidirectional relationship of these organs.

Most studies indicate that the prevalence of anemia is increased in patients with HF who also have co-morbid kidney disease, advanced age, and more severe symptoms (range, $30 \%$ to $61 \%$ ) when compared with less symptomatic ambulatory populations (range, $4 \%$ to $23 \%$ ). In patients with $\mathrm{HF}$ and preserved ejection fraction, the few published reports indicate that anemia is also highly prevalent in this group..$^{20-22}$
CKD and HF share a number of causes (eg, hypertension), features (eg, malnutrition), and risk factors (eg, older age). The relative risk of death in patients diagnosed with HF after 2 years was increased by a factor of 1.6 in anemic patients with heart failure who also had CKD in a large Medicare database. ${ }^{23}$

In patients with $\mathrm{HF}$, acute cardio-renal syndrome (CRS) is used to describe an acute decline in kidney function associated with decompensated HF. It is present in approximately $30 \%$ of patients with decompensated HF, the frequency varying according to the studied population. ${ }^{24-27}$ In more chronic forms of CRS, it may be difficult to determine what fraction of the heart or kidney dysfunction is the result of underlying primary structural disease as apposed to a functional decrease, due to dysfunction of the "other" organ. Whether acute or chronic, due initially to intrinsic heart or kidney disease, anemia is also associated with CRS and is a key factor in the pathophysiology contributing to morbidity and mortality (see Figure 1). Anemia is thought to be related to a combination of factors including chronic renal failure, bone marrow suppression through cytokine mediated mechanisms, hemodilution and medications such as angiotensin converting enzyme (ACE) inhibitors and aspirin. ${ }^{28-36}$

\section{Anemia and cardiovascular disease}

The World Health Organization defines anemia as a hemoglobin count less than $13 \mathrm{~g} / \mathrm{dL}$ in men and $12 \mathrm{~g} / \mathrm{dL}$ in women. ${ }^{37}$ If this definition were to be used, anemia is common in patients with HF. ${ }^{6}$ Additionally, anemia is common in patients with a glomerular filtration rate (GFR) of less than $60 \mathrm{~mL} / \mathrm{min}$, with increasing prevalence noted with declining GFR (see Figure 2). ${ }^{6,38}$

As stated previously, CVD is widely prevalent in patients with CKD and more so in dialysis populations. Over half of the patients who are end stage renal disease-dialysis dependent (ESRD-DD) will die of CVD and its sequelae. Parfrey et al reported that around 74\% patients have left ventricular hypertrophy (LVH), 32\% left ventricular dilatation and $15 \%$ systolic dysfunction on initiation of renal replacement therapy (RRT). ${ }^{34}$ In those on RRT, the incidence of de novo ischemic heart disease is 5\% and of HF $11 \%$ per year of RRT. ${ }^{36}$ Of key importance is the finding that having both HF and LVH predicts poorer survival in these patient populations. ${ }^{34-36}$ Levin et al looked at pre-dialysis CKD populations and noted that both hemoglobin levels and systolic blood pressure were associated with LVH. Interestingly, Levin et al also showed that the presence of anemia 


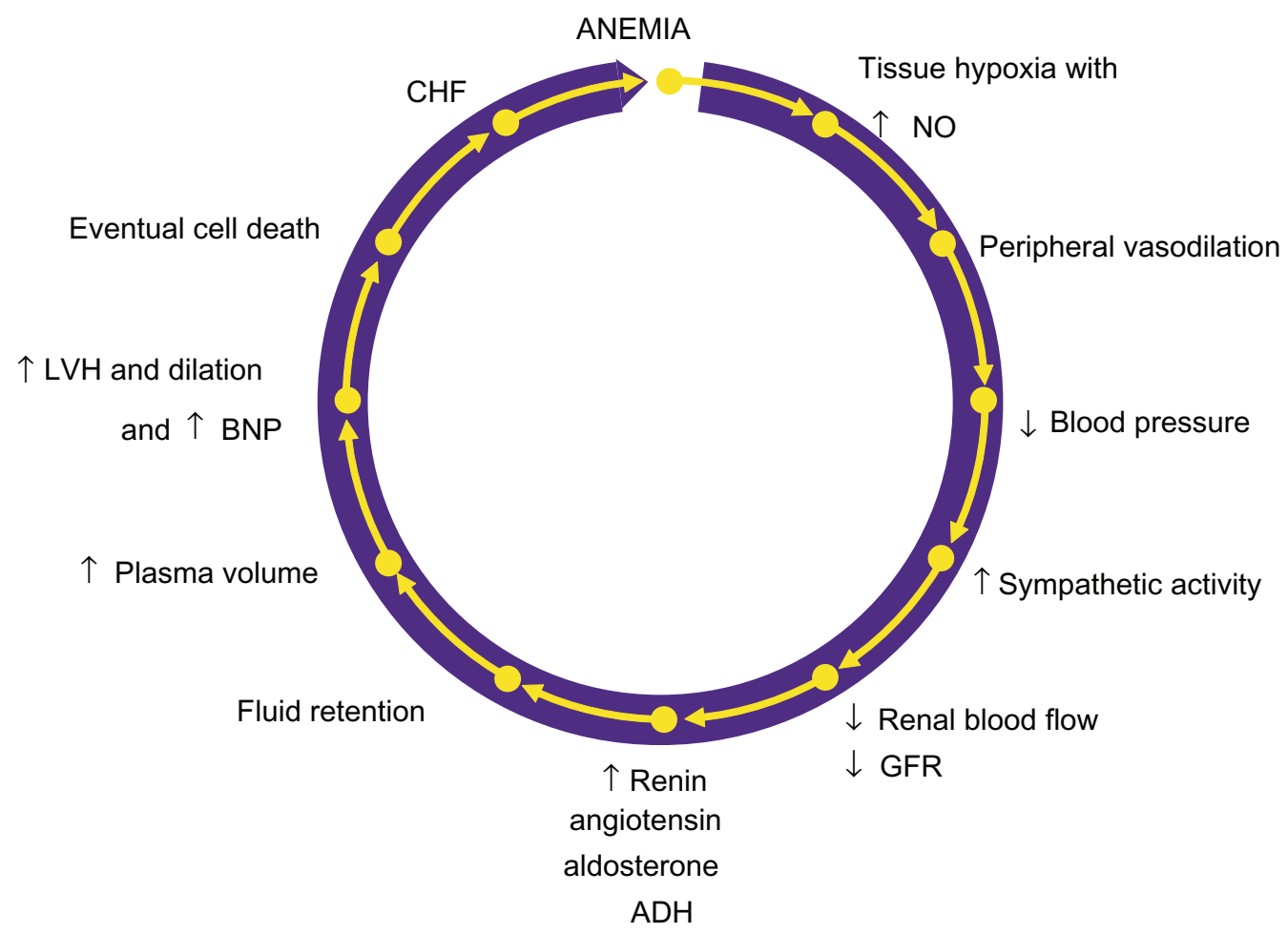

Figure I Schematic diagram showing how anemia causes fluid retention and heart failure which in turn reduced renal perfusion and produces renal dysfunction. Based on studies. $^{58,63,88,89,100,101}$

Abbreviations: BUN, blood urea nitrogen; CHF, congestive heart failure; GFR, glomerular filtration rate; LVH, left ventricular hypertrophy.

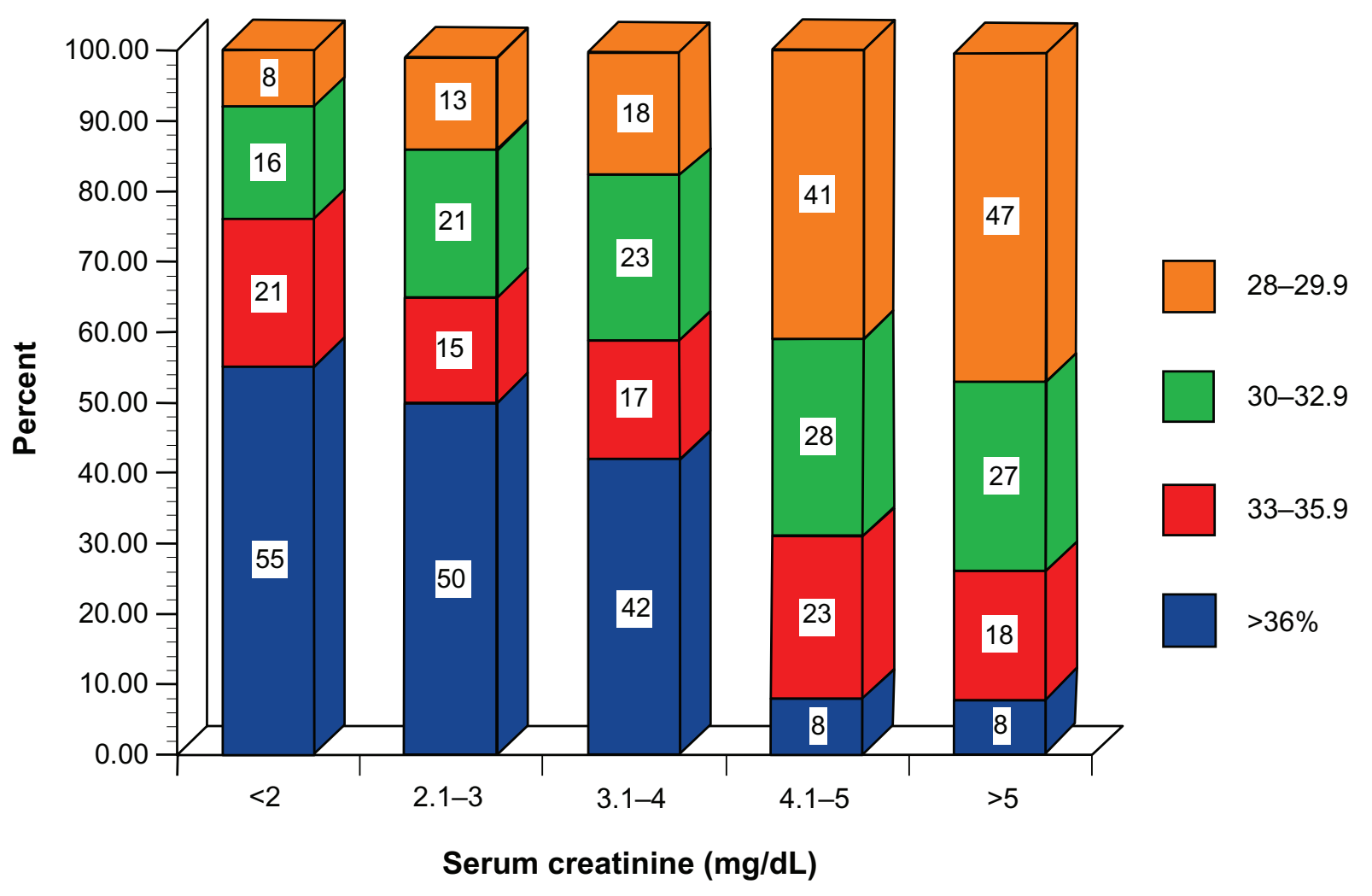

Figure 2 Relationships of the frequency and severity of anemia in a chronic kidney disease population. As renal function worsens, the fraction of subjects with hematocrit $<33 \%$ increases 3 -fold, from $24 \%$ to $74 \%$. Drawn from data of Kazmi et al..$^{38}$ 
and CVD was associated with a reduced time needed for the initiation of dialysis. ${ }^{39-41}$ The impact of anemia, CKD, and HF on mortality was assessed in a Medicare sample population as shown in Figure $3 .{ }^{42}$ The presence of CKD or HF increased the likelihood of death 2- to 2.5-fold over having neither. Anemia increased the likelihood of death to almost 4 with either covariate. Having all three increased the likelihood of death 6-fold.

\section{Pathophysiology of anemia in chronic heart failure}

The etiology and pathophysiology of anemia in HF is mutifactorial. Androne et al reviewed 196 advanced heart failure patients and reported that in a subset of 37 ambulatory HF patients with anemia, 46\% experienced anemia from hemodilution due to expansion of plasma volume rather than a true reduction in red blood cell mass, with only $54 \%$ experiencing "true anemia". ${ }^{4}$ Other mechanisms of anemia are associated with chronic disease, iron losses due to anti-platelet drugs and anticoagulants as well as urinary losses of serum erythropoeitin (EPO) and transferrin. ${ }^{43,44}$

HF itself can be considered to produce an inflammatory milieu, in which inflammatory cytokines such as interleukins $1,6,18$ and tumor necrosis factor alpha (TNF- $\alpha)$ are noted to be elevated. Higher levels of TNF- $\alpha$ are found in the circulation and in the myocardium of patients with chronic heart failure as compared to controls. TNF- $\alpha$ has been implicated in a number of pathophysiological processes that are thought to be important in the progression of chronic heart failure. ${ }^{45}$ Patients with NYHA class IV symptoms, those with cardiac cachexia and those with edematous decompensation of their disease have the highest serum TNF- $\alpha$ levels. ${ }^{46}$ These inflammatory cytokines have been reported to cause anemia in vitro. ${ }^{47}$ Cytokine-mediated responses include reduced red blood cell progenitor proliferation, with erythropoietin blunting, hepcidin elevation with resultant stunted iron absorption at the level of the intestine and the blockade of iron release from macrophages. ${ }^{48,49}$ These inhibitory effects of TNF alpha are shown schematically in Figure 4.

Both ACE inhibitors and long-term aspirin use have also been implicated in the anemia related to HF. The SOLVD trial showed a significantly higher prevalence of anemia in the Enalapril arm compared with placebo (11.3\% vs $7.9 \%$, OR 1.56). The authors hypothesized that ACE inhibitors inhibit erythroid precursor cells. ${ }^{50}$ Angiotensin II is a growth factor and ACE inhibitors lead to the formation of a tetrapeptide (N-acetyl-seryl-lysyl-proline or AcsSDKP) which is an endogenous inhibitor of erythropoiesis. ${ }^{51}$ This property of ACE inhibitors to inhibit erythrocytosis is used therapeutically in polycythemic patients and in the setting

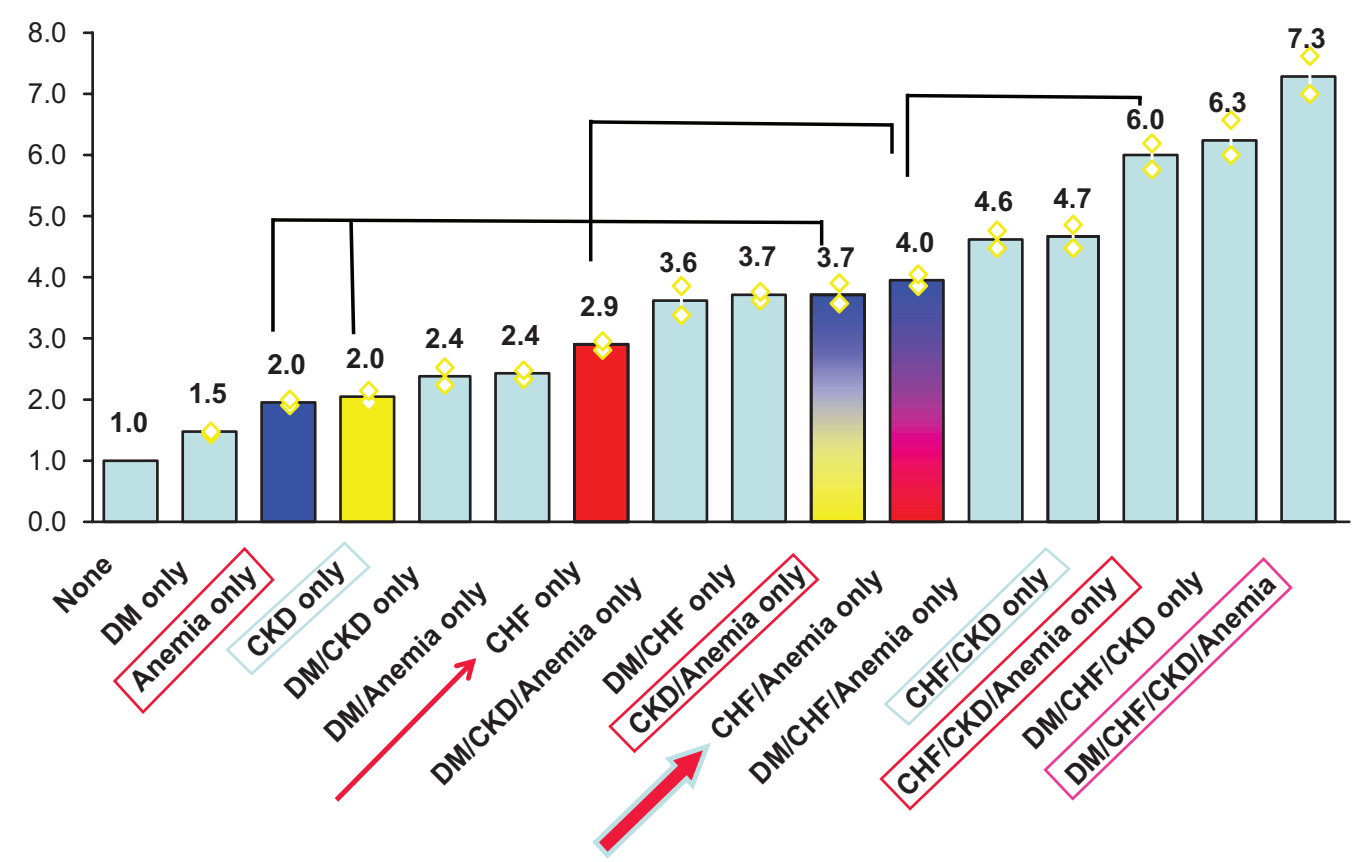

Figure 3 Likelihood for death before end stage renal disease during 2-year of follow-up in Medicare 5\% sample: 1996-1997, aged >65 on I/I/96. Odds ratios adjusted for age, gender, and race. ICD 9 codes for anemia 280.xx through 285.xx. Note how the likelihood of death increases as anemia, CKD, and CHF are combined as comorbid conditions. Drawn from data of Collins et al. ${ }^{42}$

Abbreviations: CHF, congestive heart failure; CKD, chronic kidney disease; DM, diabetes. 


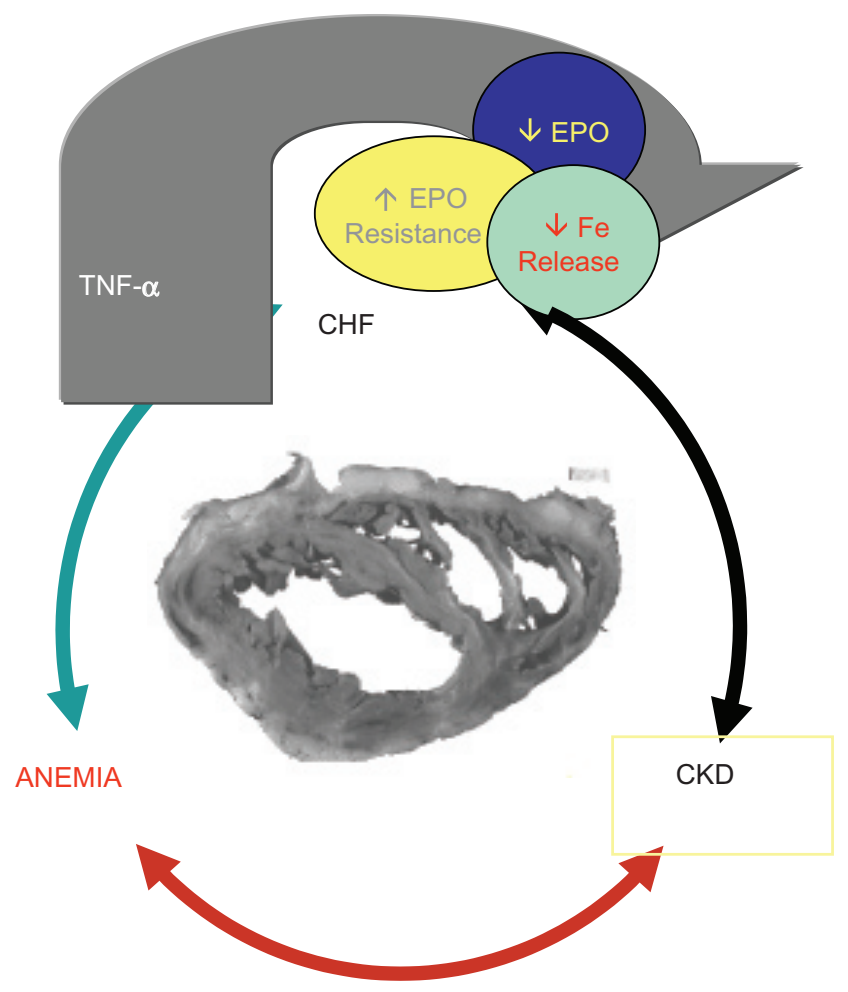

Figure 4 The influence of cytokines in the development of anemia in the cardiorenal anemia syndrome. TNF- $\alpha$ and other cytokines have an inhibitory effect on erythropoietin-stimulating agent-dependent erythropoietic processes in the bone marrow (EPO resistance), inhibit remobilization for hemoglobin synthesis through hepcidin production, and decrease endogenous EPO production in the kidney. Anemia worsens heart failure, decreases renal perfusion, and leads to a circular cycle. Abbreviation: CKD, chronic kidney disease.

of post transplant erythrocytosis. Anemia from long term Aspirin use is thought to be related to masked gastrointestinal blood losses. Other contributing factors in the pathogenesis of anemia include phlebotomy, the induction of a ferropenic state and EPO resistance which is thought to increase with HF severity.

\section{Serum erythropoeitin levels and HF}

EPO levels have been shown to be elevated in HF. Volpe et al noted that plasma EPO levels increased with worsening NYHA classification, the exact significance of this finding is not fully understood but could be a physiological response to increasing anemia as HF worsened. ${ }^{52}$ In a Netherlands study, Van der Meer and colleagues retrospectively examined 74 Caucasian patients with mild to advanced HF. During the mean follow up of 3 years they found that anemia was present in $24 \%$ of patients, and that increased plasma EPO levels were associated with increased mortality, independent of hemoglobin levels. Interestingly, they also noted that in HF patients, EPO levels did not correlate with the hemoglobin levels. ${ }^{53}$ This lack of a quantitative relationship in the degree of anemia, as reflected by hemoglobin and EPO levels in $\mathrm{HF}$, is paralleled by a similar observation in patients with varying stages of CKD. ${ }^{54}$ Evidently the effect of circulating inflammatory cytokines at multiple sites, including EPO production as well as the erythropoietic action of EPO in the bone marrow, interferes with the normal operation of the feedback system so that it produces an inverse relationship of hemoglobin to EPO levels.

\section{The spectrum of cardio-renal syndrome}

The generic definition of CRS is used to describe an acute decline in kidney function in patients with decompensated heart failure. The pathophysiology in organ discordance is still largely poorly understood but is thought to be related to a complex interplay between a structurally failing heart, sympathetic, neurohumoral and inflammatory mediators resulting in renal vasoconstriction with ischemia contributing in a reduced GFR. However, many have argued that this definition is too simplistic, ambiguous and lacked widespread uniformity causing confusion. ${ }^{7,24,49,55}$ Ronco et al argued that communication of both organs was indeed "bi-directional", where one organ, whether heart or kidney, could lead to the dysfunction of the other. With this thought process in mind, Ronco proposed a classification system that would take into account the chronology of the initial organ failure and the pathophysiological coping communication interplay that ensues. Ronco et al classified CRS into 5 subtypes, giving CRS some degree of uniformity. ${ }^{25-27}$

- CRS type 1 (acute CRS): characterized by a rapid worsening of cardiac function, leading to acute kidney injury (AKI). This is thought to be the most common type with AKI conferring the worst prognosis.

- CRS type 2 (chronic CRS): characterized by chronic abnormalities in cardiac function (eg, chronic congestive HF) causing progressive CKD, thus measuring serum creatinine in this setting can often be misleading.

- CRS type 3 (acute renocardiac syndrome): characterized by an abrupt and primary worsening of kidney function (eg, AKI, ischemia, or glomerulonephritis).

- CRS type 4 (chronic renocardiac syndrome): characterized by a condition of primary CKD (eg, chronic glomerular disease).

- CRS type 5 (secondary CRS): characterized by the presence of combined cardiac and renal dysfunction due to acute or chronic systemic disorders.

The pathophysiology of worsening renal function in CRS is depicted in Figure 5. 


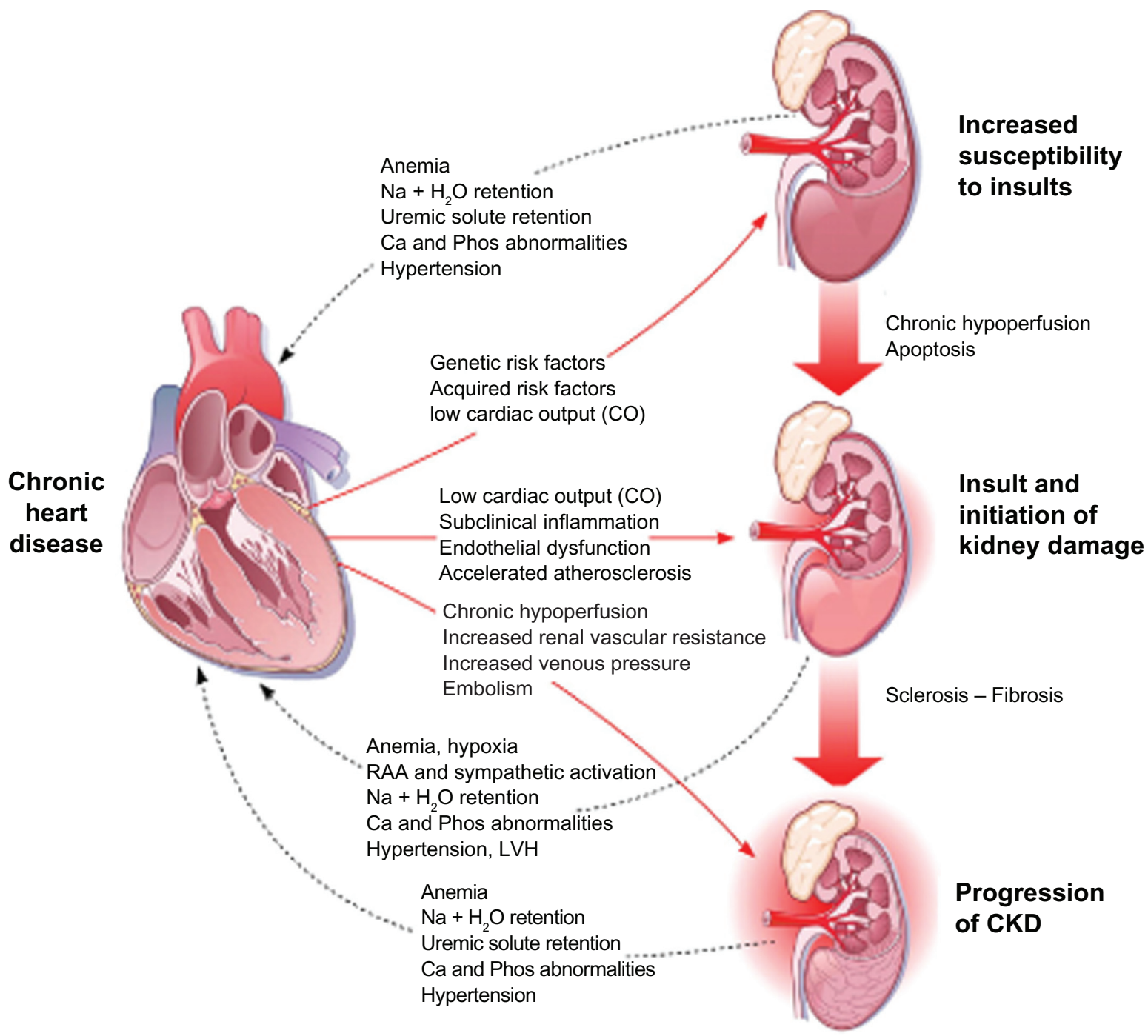

Figure 5 Pathophysiology of worsening renal function in cardio-renal syndrome.

Reproduced with permission from Horwich TB, Fonarow GC, Hamilton MA, MacLellan WR, Borenstein J. Anemia is associated with worse symptoms, greater impairment in functional capacity and a significant increase in mortality in patients with advanced heart failure. J Am Coll Cardiol. 2002;39(I I): I780-I 786. ${ }^{64}$ Copyright (C) 2002 Elsevier:

Abbreviation: CKD, chronic kidney disease.

\section{Why is CRS important?}

The Analysis of the Acute Decompensated Heart Failure National Registry (ADHERE) was set up in part to address this question. ${ }^{56,57}$ The results showed that the risk of inpatient mortality was significantly increased if patients exhibited the following: a blood urea nitrogen (BUN) of greater than $42 \mathrm{mg} / \mathrm{dL}$; serum sodium less than $134 \mathrm{mmol} / \mathrm{L}$, creatinine greater than $3.2 \mathrm{mg} / \mathrm{dL}$, an age greater than 78 , dyspnea at rest, systolic blood pressures less than $115 \mathrm{mmHg}$ and diastolic readings less than $55 \mathrm{mmHg}$ (Table 1). The main limitation of ADHERE is that the study was retrospective, the data observational, and thus the relationships are associative and not necessarily causal. ${ }^{56}$ In 2006 , Smith et al reviewed and conducted a metanalysis of 16 studies that looked at more than 80,000 patients with HF. They found after a 1 year follow up mortality was significantly higher in patients with moderate to severe renal impairment, compared with those with normal kidney function or even mild impairment. ${ }^{2}$ Furthermore, impaired renal function is consistently found as an independent predictor for 1 year mortality in acute heart failure patients. An elevated BUN even without a reduction in GFR was highlighted as a poor prognostic marker by Aronson et al, a finding substantiated in the ACTIV in CHF study. ${ }^{58,59}$ This paradoxical finding is thought to be secondary to renal hypoperfusion contributing to pre-renal azotemia. Silva and colleagues explored this further and noted that both an increased serum creatinine and a low ejection fraction (EF) were associated with increased death, a finding also supported by Dries et a ${ }^{60}$ In a large scale study, Gottlieb et al showed that a serum creatinine increase 
Table I Predictors of inpatient mortality in patients with decompensated heart failure

\begin{tabular}{|c|c|c|c|}
\hline Variable & $\begin{array}{l}\text { Died } \\
(n=2675)\end{array}$ & $\begin{array}{l}\text { Survived } \\
(n=62,505)\end{array}$ & $\begin{array}{l}\text { OR of death } \\
(95 \% \mathrm{Cl})\end{array}$ \\
\hline Age $>78$ vs $\leq 78$ & & & $1.88(1.74-2.04)$ \\
\hline BUN $>42$ vs $\leq 4.2$ & & & $3.34(3.08-3.62)$ \\
\hline $\mathrm{Cr}>3.2$ vs $\leq 3.2$ & & & $1.99(1.78-2.24)$ \\
\hline$S B P \leq 115$ vs $>115$ & & & $3.09(2.85-3.35)$ \\
\hline $\mathrm{DBP} \leq 55$ vs $>55$ & & & $2.87(2.62-3.14)$ \\
\hline Sodium $\leq 134$ vs $>134$ & & & $2.26(2.08-2.47)$ \\
\hline Dyspnea at rest, n (\%) & $1220(46 \%)$ & 21,757 (35\%) & $\mathrm{I} .57(\mathrm{I} .45-\mathrm{fl} .70)$ \\
\hline
\end{tabular}

From data of Abraham et al..$^{56}$

Abbreviations: $\mathrm{BUN}$, blood urea nitrogen; $\mathrm{Cl}$, confidence interval; $\mathrm{Cr}$, serum creatine; $\mathrm{OR}$, odds ratio; DBP, diastolic blood pressure; SBP, systolic blood pressure.

of greater than $0.3 \mathrm{mg} / \mathrm{dL}$ from baseline had a specificity of $81 \%$ in predicting inpatient hospital mortality. ${ }^{61}$

\section{Associations between cardiorenal syndrome and anemia}

For many years the existence of anemia with CRS was widely ignored, but more recently its role as a prognosticator for morbidity and mortality has been elucidated. The importance of anemia as a risk factor for progressive HF was highlighted as far back as 1987 in the Framingham Study. ${ }^{62}$ Anemia has been revisited more recently as an independent predictor of mortality, although with inconsistent results. The true prevalence of anemia in CRS is variable, depending upon the studied population, ranging anywhere from $4 \%$ to $55 \%$, with increased incidence noted with worsening NYHA classification, and approaching $79 \%$ in those with NYHA class IV. ${ }^{3,28,48,63-65}$

\section{Anemia as a predictor of morbidity and mortality}

Anemia has been associated with worsening structural heart disease; diastolic dysfunction, LVH, increased left ventricular mass index and higher pulmonary heart pressures. Clinically, anemia is associated with worsening symptoms, increased diuretic use, medically refractory heart failure and reduced mixed venous oxygen saturation, and contributes to "cardiac cachexia" and is associated with increased hospitalizations ${ }^{66}$ and re-hospitalizations ${ }^{67}$ Small studies, often observational have indicated that the presence of and severity of anemia can worsen an NYHA classification in those with HF. These findings have been championed by Silverberg and colleagues. Their observations have prompted more rigorous attention to be paid to anemia correction and management.
In the SOLVD trial, low hemoglobin was found to be an independent predictor of mortality at a mean follow up of 33 months (see Figure 6), with a higher mortality associated with a hematocrit (Hct) of less than 35 (34\%) compared with Hct greater than 40 (22\%). ${ }^{50}$ Survival rates steadily declined with each decrease in hemoglobin deciles, with no evidence of a U-shaped relationship. ${ }^{64}$ Silverberg and colleagues have shown repeatedly that the presence of anemia in HF is associated with increased mortality (see Figure 7)., $3,28,63$

This has been further verified by Kosiborod et al, who looked at 2281 patients that were admitted with a diagnosis of HF between 1994 and1995. In both adjusted and non adjusted analysis, serum Hct remained an independent predictor for of 1 year mortality, - with increased mortality in patients with Hct $<27 \%$ compared to those with $>42 \%$. They also noted that patients with $\mathrm{EF} \leq 20 \%$ had higher mortality at one year compared with patients with $\mathrm{EF} \geq 40 \%$ (hazard ratio $[\mathrm{HR}]=1.50 ; 95 \%$ confidence interval $[\mathrm{CI}] 1.20$ to 1.86 ; $P=0.0001$ ). Not surprisingly, patients with a low hemoglobin had a higher rate of re-admissions, with $2 \%$ associated increased risk with each 1\% drop in Hct (HR 1.02; $95 \%$ CI 1.01 to $1.03 ; P=0.0002) .{ }^{68}$

In 2002, Horwich and colleagues, evaluated a cohort of 1061 patients with NYHA class III-IV, with an EF $<40 \%$. They divided patients into 4 groups: those with a hemoglobin $<12.3 \mathrm{~g} / \mathrm{dL}$, hemoglobin 12.3 to $13.6 \mathrm{~g} / \mathrm{dL}$, hemoglobin 13.7 to $14.8 \mathrm{~g} / \mathrm{dL}$ and with hemoglobin $>14.8 \mathrm{~g} / \mathrm{dL}$. They found that patients in the lower hemoglobin quartiles were more likely to have HF class IV $(P=0.0001)$; increased survival was noted in the higher hemoglobin quartile. On multivariate analysis they found that hemoglobin acts as an independent predictor for 1-year mortality with mortality increasing as hemoglobin decreased below $14 \mathrm{~g} / \mathrm{dL}$ (Figure 7) ${ }^{64}$ Ezekowitz and coworkers simply dichotomized 12,065 patients with new onset HF into those with or without anemia as defined by the lower limits of normal by gender. After adjustment for clinical and demographic variables, patients with anemia were more likely to be older (odds ratio [OR] 1.01 per year) and female (OR 1.2 [95\% confidence interval 1.1 to 1.3$]$ ) and to have a history of chronic renal insufficiency (OR $=3.2 ; 95 \%$ CI 2.8 to 3.6]), or hypertension (OR $1.3 ; 95 \%$ CI 1.2 to 1.5$]$ ). Hazard ratios for mortality, adjusting for covariates, were 1.34 (1.24 to 1.46) in anemic patients, and 1.36 (1.23 to 1.50) in those patients with anemia of chronic disease. An absolute difference of 15 percentage points in survival developed within 1 year ( 75 vs $60 \%$ ) in non-anemic compared anemic patients, a difference maintained for the next 4 years (see Figure 8) ${ }^{69}$ In a retrospective 


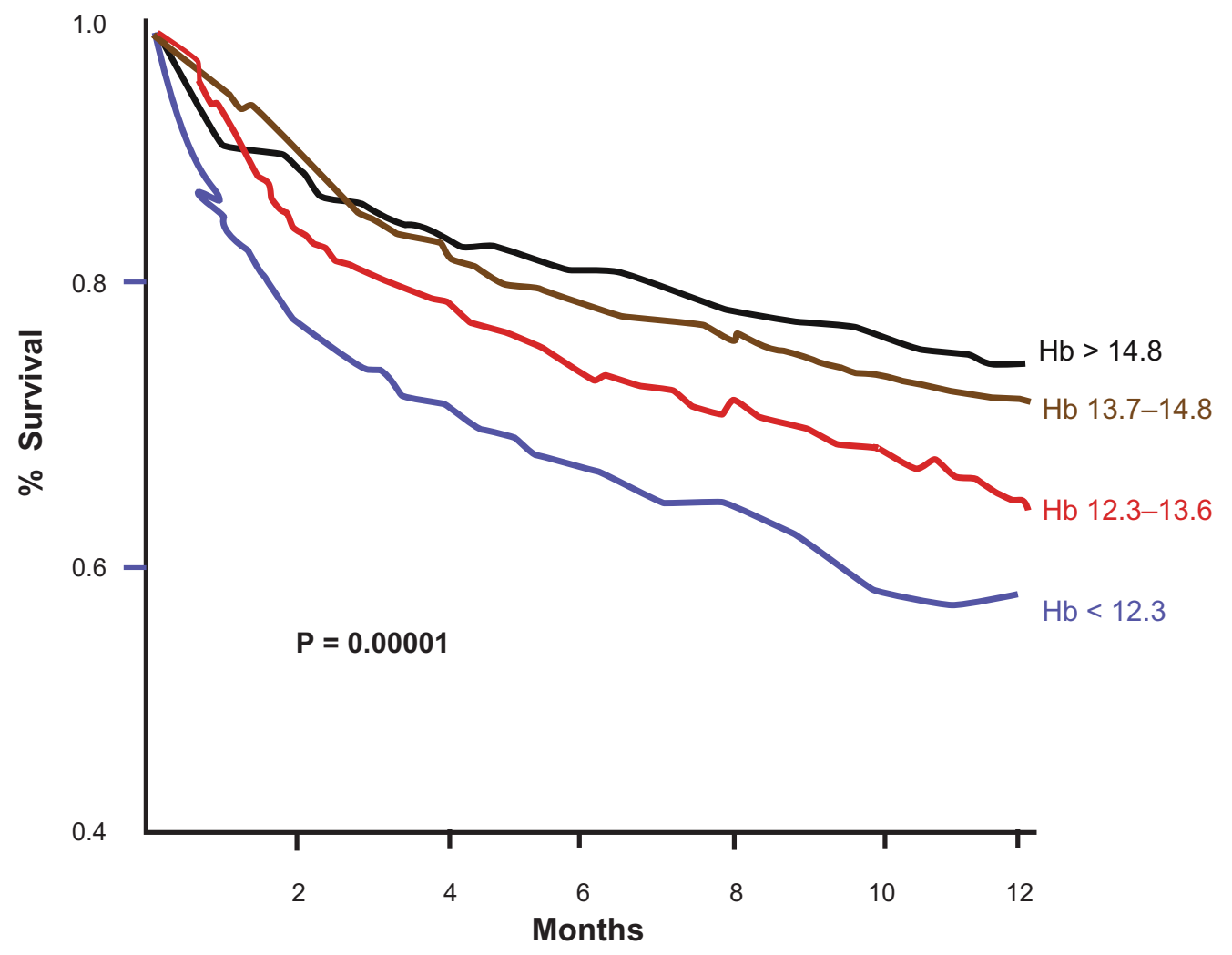

Figure 6 Post-hoc analysis of the influence of severity of anemia on survival of patients in the SOLVD clinical trial. Drawn from data of Horwich et al. ${ }^{64}$

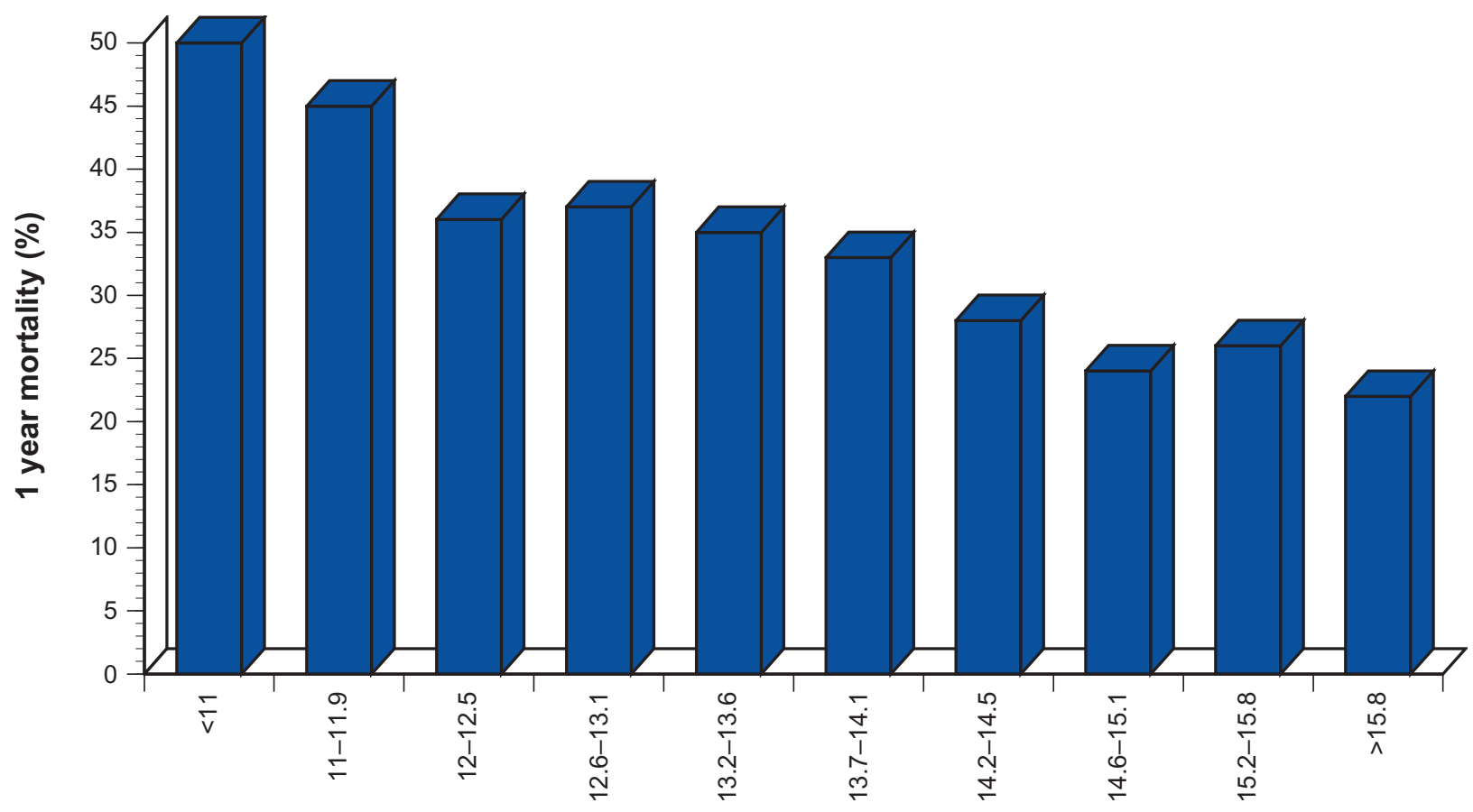

Hemoglobin deciles

Figure 7 One-year mortality rates in a cohort of heart failure patients by deciles of hemoglobin level. Drawn from data of Horwich et al. ${ }^{64}$ 


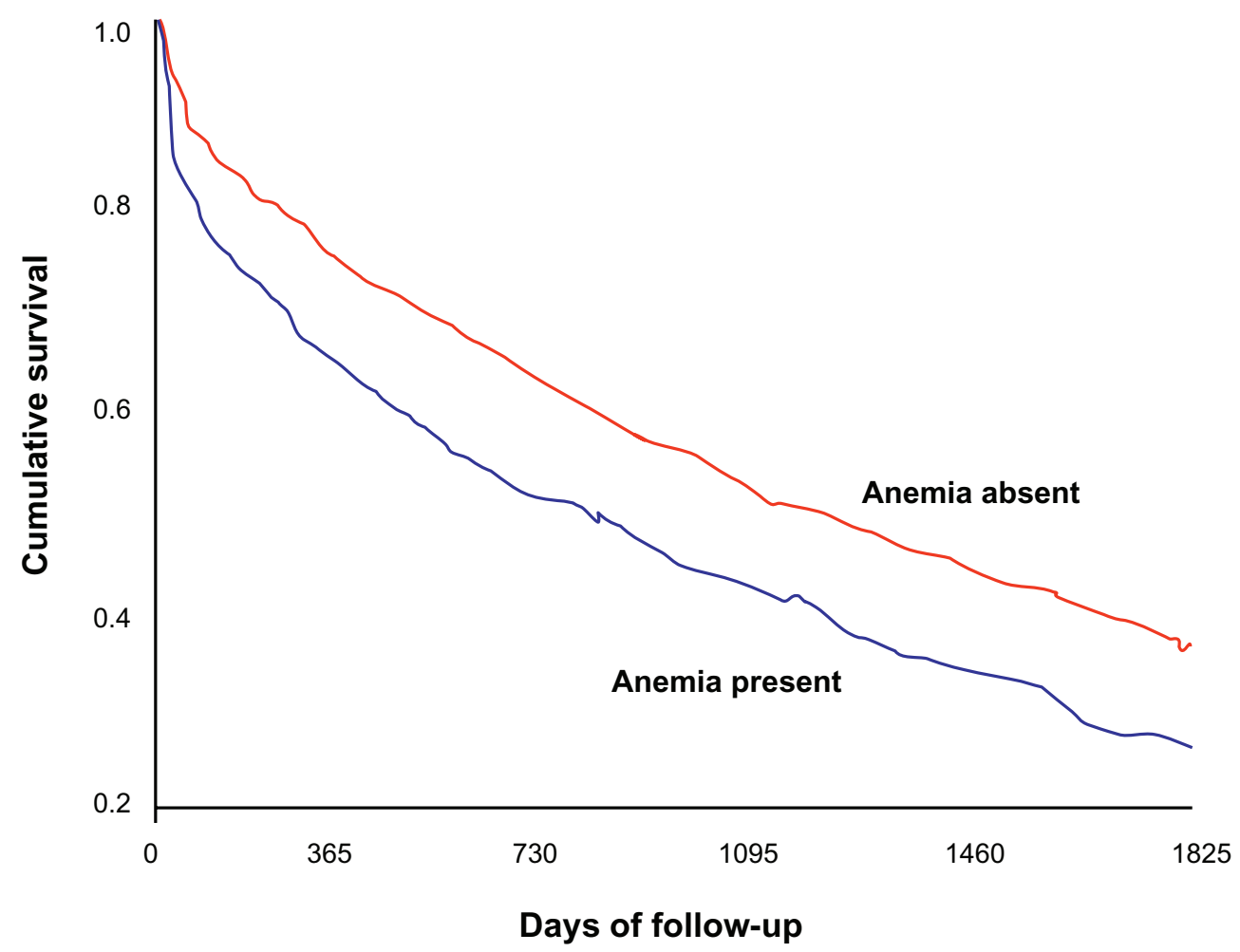

Figure 8 Survival of heart failure patients with and without anemia at the time of initial diagnosis of heart failure. Note: Survival curves were generated using Kaplan-Meier methods $(P<0.000$ I for anemia present versus anemia absent). Drawn from data of Ezekowitz et al. 2003.69

analysis of Studies of LV Dysfunction (SOLVD) database, evaluation of the interaction between the level of Hct and the level of GFR on all-cause mortality suggests that anemia and reduction in kidney function are more than additive as risk factors. In fact, the relative risk of death rises with a drop in Hct for each level of GFR (see Figure 9). ${ }^{70}$

In the Outcomes of a Prospective Trial of Intravenous Milrinone for Exacerbations of Chronic Heart Failure (OPTIME-CHF) study, hemoglobin levels were noted to be an independent risk factor for death and re-hospitalization with every $1 \mathrm{~g} / \mathrm{dL}$ drop in hemoglobin. ${ }^{71}$ Szachniewicz and colleagues conducted a prospective study looking at 176 patients; their primary endpoint was to determine the all-cause mortality. They noted, as with other studies, that patients with symptomatic $\mathrm{HF}$ as evidenced by a worsening NYHA classification had lower hemoglobin levels. On Kaplan-Meier survival curves they found that the 18-month survival in HF patients with anemia was clinically significant compared with those with normal hemoglobin levels. ${ }^{72}$ The PRAISE study, was a prospective multi-center study, that evaluated in 1130 patients the associations of $\mathrm{EF}<30 \%$, NYHA classification functional class IIIB or IV, and baseline Hct to the most important outcome, patient mortality. ${ }^{5}$ The findings indicated that anemia was an independent predictor for mortality in patients with severe HF. Patients with Hct of $25.4 \%$ to $37.5 \%$, were noted to have worse mortality, and every $1 \%$ decrease in Hct was associated with a $11 \%$ higher risk of mortality. ${ }^{5}$ A recent meta-analysis of 34 studies describing HF and anemia by Groenveld and others, identified 153,180 HF patients of whom $37.2 \%$ were anemic (see Figure 10). After a minimal follow-up of 6 months, $46.8 \%$ of anemic patients had died compared with $29.5 \%$ of non-anemic patients. Crude mortality risk of anemia had an odds ratio of 1.96 (95\% CI 1.74 to 2.21; $P<0.001)$. Lower baseline hemoglobin values were associated with increased crude mortality rates $(\mathrm{r}=-0.396 ; P<$ $0.025)$. Adjusted hazard ratios showed an increased adjusted risk for anemia (HR 1.46; 95\% CI 1.26 to $1.69 ; P=0.001]$ ). Subgroup analysis showed no significant difference between mortality risk of anemia in diastolic or systolic $\mathrm{HF}^{73}$

Whether or not the effect of anemia is truly a directly independent effect cannot be readily determined by such associative studies since both anemia and degree of HF may be due to other variables, particularly co-morbid conditions which then create pitfalls in interpreting current observational studies examining anemia and HF. Many studies have postulated a causal relationship between anemia and HF without adjusting for other co-morbidities, making data analysis questionable. To examine for such a possibility, Kalra 


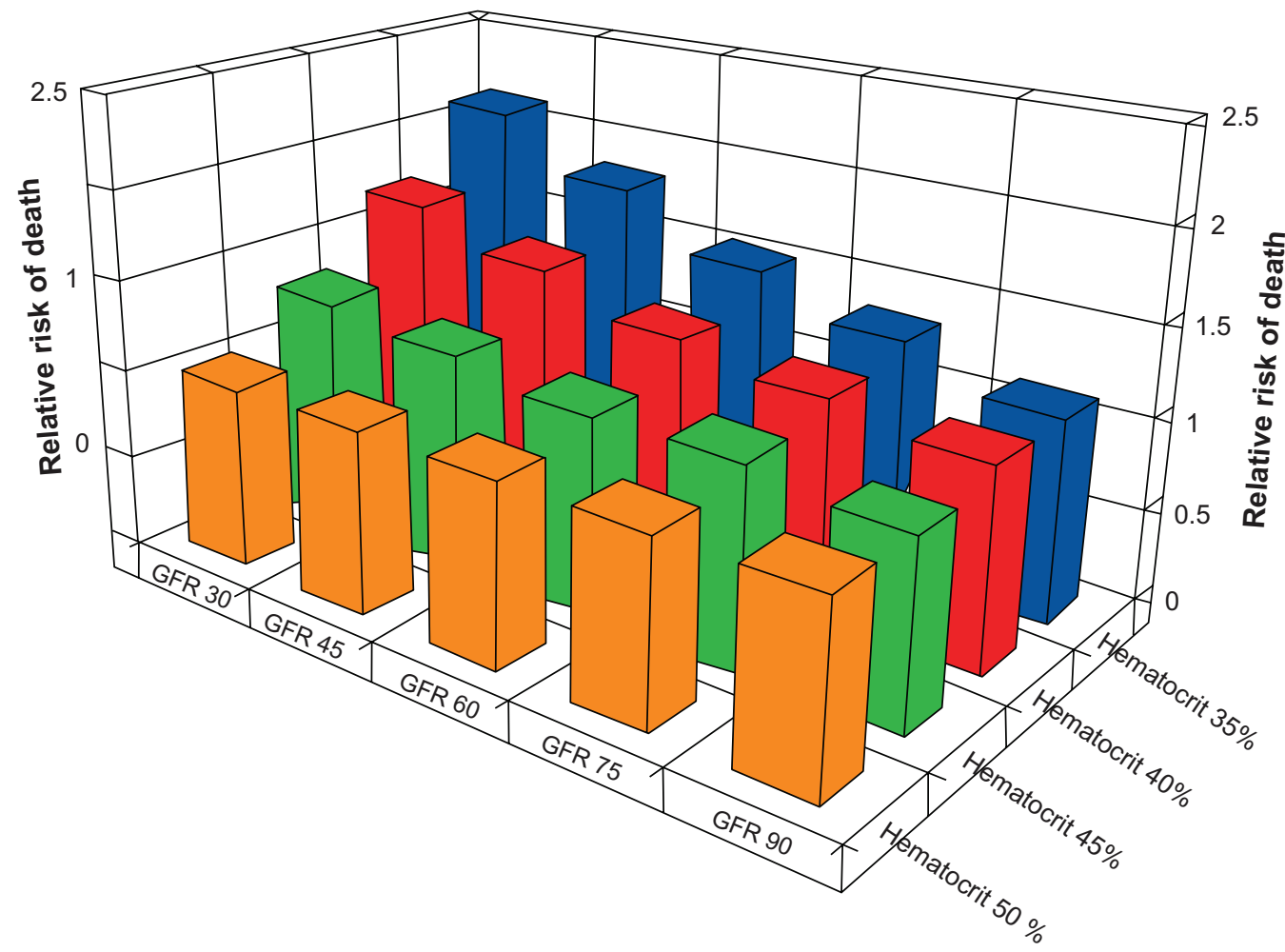

Figure 9 Survival of heart failure patients by level of glomerular filtration rate and hematocrit.

Notes: GFR in $\mathrm{mL} / \mathrm{min} / \mathrm{l} .73 \mathrm{~m}^{2}$.

Drawn from data of Al-Ahmad et al. 2001. ${ }^{70}$

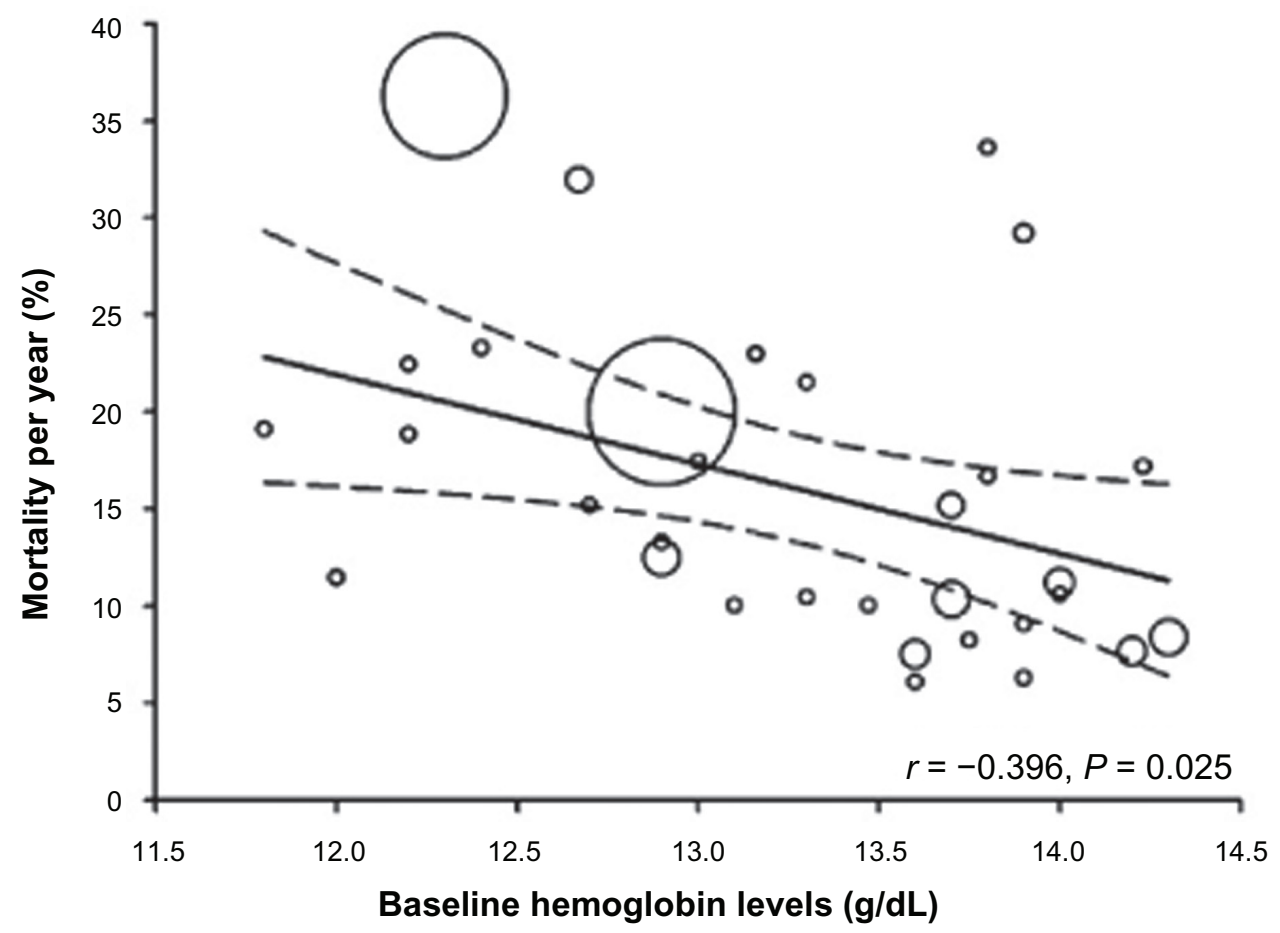

Figure 10 Relationship between baseline hemoglobin and annual mortality in patients with heart failure.

Notes: The area of each circle is proportional to the sample size in each cohort. The center line shows the estimated mortality risk per year of lower baseline hemoglobin values on a continuous scale. The dotted lines represent $95 \%$ confidence intervals.

Drawn from data of Groenveld et al. $2008 .^{73}$ 
et al studied 552 patients with new onset HF, although they found a significant increase in the incidence of anemia they did not find it to be an independent covariate for worsening outcomes when they adjusted for other variables, specifically co-morbidities. ${ }^{74}$

\section{Anemia, CKD and HF}

Such confounding results are also present in studies of HF complicated by the presence of CKD and anemia. In a retrospective analysis by McClellan et al who looked at 755 patients, who were discharged from community hospitals, with a diagnosis of heart failure. ${ }^{17}$ They found that the 1-year death rate with patients with and without a diagnosis of CKD were $44.9 \%$ and $31.4 \%$, respectively (relative risk 1.43; $95 \%$ CI 1.17 to 1.75$)$. An Hct was recorded for 633 patients, with increasing prevalence of anemia with $\mathrm{CKD}$, the anemia being of greater severity with worsening GFR. Strikingly, they found the one year mortality to be $31.2 \%$ in patients with an admission Hct of $\geq 40 \%$ and $50 \%$ in those with an admission Hct of $30 \%$ to $35 \%$. After multivariate analysis they concluded that both hematocrit and serum creatinine were independently associated with increased mortality. Unfortunately, the investigators had to use admission Hct which could have been confounded by varying degrees of hemodilution. ${ }^{6}$ Herzog et al examined a cohort of $1,136,201$ patients using the $5 \%$ general Medicare data base, who were enrolled in both Medicare Part A and Part B. To decipher whether anemia itself was an independent risk factor, they applied co-morbidity-adjusted relative risks to each disease state. They noted that patients with both CKD and HF were 3.3 times more likely to die as compared to the reference population, additionally, they showed that there was a 4-fold increased probability of death if a patient exhibited anemia, CKD and HF. They found that both anemia and CKD served as independent mortality risk factors in the elderly population (see Figure 3 ).${ }^{75}$ One criticism of this large cohort study is that it shows only associations between disease states and these correlations should not be misinterpreted as "cause and effect."

\section{Educating care providers}

Despite these observations, anemia in both HF and CRS is under treated and under recognized. Silverberg et al writing in the Dialysis Times, refer to data obtained in the Cleveland clinic looking at 2011 ambulatory patients with HF; it was estimated that anemia was only recognized in $11.1 \%$ of patients and that only a disappointing $10 \%$ of those diagnosed with anemia were treated for their anemia. ${ }^{28}$ The treatment and management of anemia in CRS requires a multidisciplinary approach in addition to educating internists, cardiologists and hematologists alike. Silverberg et al noted an 8-fold increase in anemia referral to nephrologists after in hospital meetings with cardiologists, hematologists and internists. $^{76}$

\section{Treatment of anemia and correction of cardiac disease}

In HF small differences in hemoglobin are associated with worse outcomes and symptoms. Correction and management of anemia have been shown to improve NYHA classification, LVEF, LVH and diuretic response in some small studies. Additionally, in some small studies better outcomes and reduced rates of re-hospitalization occur after anemia treatment. ${ }^{3,77-80}$ Yet, anemia treatment and management in HF are controversial, partly because anemia is under recognized and diagnosed and there in no consensus as when to begin therapy or which agents to use. Treatment and management has centered on erythropoietin-stimulating agents (ESAs) and parenteral iron supplementation. Unfortunately, most studies are small, non-randomized or blinded, and consequently poorly powered, limiting their validity. In a study of 37 patients with CHF, iron-deficiency anemia was confirmed by bone marrow aspiration in 27 patients $(73 \%), 2$ patients $(5.4 \%)$ had dilutional anemia, and 1 patient $(2.7 \%)$ had druginduced anemia. No specific cause was identified in 7 patients $(18.9 \%)$ who were considered to have "anemia of chronic disease." Serum ferritin for the iron-deficient patients was not a reliable marker of iron deficiency in this population. Thus, the authors concluded that in this group of patients, iron deficiency was the most common cause of anemia. The iron status of patients with end-stage chronic CHF should be thoroughly evaluated and corrected before considering any other therapeutic interventions. ${ }^{13}$

Silverberg and colleagues examined the benefits in correcting anemia using a combination of intravenous iron (iron sucrose) and ESAs in the form of subcutaneous EPO. ${ }^{3}$ They randomized patients with severe HF (NYHA class III-IV) with hemoglobin levels of 10 to $11.5 \mathrm{~g} / \mathrm{dL}$ into 2 groups, a control group (no anemia correction, 16 patients) and a treatment group (16 patients, receiving EPO and intravenous iron to correct hemoglobin $>12.5 \mathrm{~g} / \mathrm{dL}$ ). They noted that with anemia correction diuretic response, in patient hospital stay, EF, serum creatinine and ferritin improved. ${ }^{3}$ The required dose of diuretics targeting the loop of Henle was markedly decreased. Although, ESAs have been noted to produce worsening hypertension, at least theoretically, this is not a finding that was substantiated by the treated arm. In another 
larger study, Silverberg and colleagues enrolled 126 anemic HF patients with NYHA class III-IV, with hemoglobin $<11.5 \mathrm{~g} / \mathrm{dL}$. They noted a marked improvement in NYHA classification, LVEF and shortness of breath and fatigue as measured by a visual analogue scale and a significant reduction in the number of hospitalizations after anemia correction. ${ }^{63,81}$ Additionally, serum creatinine remained unchanged, and NYHA HF staging improved by 1 full grade (see Table 2). The effects of ESAs on hypertension were inconsequential. ${ }^{81}$ A single-blind, placebo-controlled, randomized trial by Mancini et al evaluated the effect of 3 months of ESAs (EPO) treatment on the exercise capacity in 26 patients with NYHA functional class III-IV. They demonstrated that the ESA-treated group had significantly improved their peak oxygen consumption. ${ }^{82}$ Unfortunately, these studies are limited by their small sample size, with a need for larger studies to substantiate their validity and applicability. Van Der Meer and colleagues explored this further through a meta-analysis. They identified 7 randomized controlled studies with 650 HF patients of which 363 were treated with ESAs and 297 with placebo. All patients identified were in NYHA II or III, in all but one study patients had Hct of $<40 \%$. They found that patients treated with ESAs had a $47 \%$ reduction in $\mathrm{HF}$ related hospitalizations. They did not find a difference in mortality between the two groups, or any increase in risk of hypertension or venous thrombosis in the ESAs treated arms, ${ }^{83}$ but the sample size may have still been too small. ${ }^{83}$ Silverberg reported on an analysis of 10 RCTs. These studies succeeded in raising mean hemoglobin to 12 to $13 \mathrm{~g} / \mathrm{dL}$,

Table 2 Values before and after treatment of anemia in 126 consecutive HF patients

\begin{tabular}{lll}
\hline & Before & After \\
\hline Hemoglobin $(\mathrm{g} / \mathrm{dL})$ & $10.3 \pm 1.4$ & $13.1 \pm 1.3^{*}$ \\
Hematocrit $(\%)$ & $30.6 \pm 4.1$ & $41.8 \pm 32.3^{*}$ \\
Serum creatinine $(\mathrm{mg} / \mathrm{dL})$ & $2.4 \pm 1.1$ & $2.3 \pm 1.2$ \\
$\Delta$ in GFR (mL/min/month) & $-0.95 \pm 1.19$ & $+0.27 \pm 1.39^{*}$ \\
NYHA (0-4) & $3.8 \pm 0.3$ & $2.7 \pm 0.6^{*}$ \\
Ejection fraction & $33.2 \pm 0.3$ & $39.6 \pm 11.1^{*}$ \\
Fatigue/SOB index (0-10) & $8.9 \pm 1.4$ & $2.7 \pm 1.9^{*}$ \\
Hospitalizations $(\mathrm{n})$ & $3.7 \pm 3.5$ & $0.2 \pm 0.5^{*}$ \\
SBP & $132 \pm 22.2$ & $131.6 \pm 27.9$ \\
DBP & $75.2 \pm 11.7$ & $76.2 \pm 11.8$ \\
\hline
\end{tabular}

From data of Silverberg et al. 2001.81

*At least $P<0.05$.

Abbreviations: GFR, glomerular filtration rate; NYHA, New York HeartAssociation; SOB, shortness of breath; DBP, diastolic blood pressure; SBP, systolic blood pressure. with no adverse effects and some benefits. The use of ESAs with oral or intravenous iron (in controlled and uncontrolled studies) has been associated with significant improvements in exercise capacity, oxygen utilization, LVEF, LVH and dilation, NYHA classification, BNP, renal function, fatigue, caloric intake and overall quality of life. ${ }^{84}$

Although these analyses are thought provoking, there is a need for a large powered randomized phase III trial. The STAMINA-HeFT study, a double-blind randomized, placebo controlled, multi-center trial, was set up to examine the effect of an ESA, darbepoetin alpha (DA) treatment on exercise tolerance; secondary endpoints included the effects of anemia treatment by DA on clinical symptoms and outcomes. The study duration was 8 months, enrolling a total of 319 patients: 157 randomized to placebo and 162 to the DA arm. At baseline the median hemoglobin was $11.4 \mathrm{~g} / \mathrm{dL}$. By week 12, the median hemoglobin in the DA-treated group had increased by $1.8 \mathrm{~g} / \mathrm{dL}$ compared to $0.3 \mathrm{~g} / \mathrm{dL}$ for placebo $(P<0.0001)$. Intent to treat analysis showed that DA did not significantly improve exercise duration, NYHA class, or quality of life score compared with the placebo group. A non-significant trend was observed toward a lower risk of all-cause mortality or first HF hospitalization in DA treated patients compared with placebo (HR 0.68; 95\% CI $0.43,1.08 ; P=0.10) .{ }^{85}$ Similar findings were noted in a separate controlled trial of darbepoetin with 173 patients. ${ }^{86}$ It should be noted that in these two studies, no differences occurred in mortality or in the incidence of hypertension, venous thrombosis, pulmonary embolus, cerebrovascular disorder, myocardial infarction or other cardiovascular events. Data are awaited from the ongoing Reduction of Events with Darbepoetin alfa in Heart Failure (RED-HF) study, a double-blind, multi-centered, placebo-controlled trial of darbepoetin in anemic HF patients which now includes over a thousand patients treated for 6 to 18 months and has a hemoglobin target of $13 \mathrm{~g} / \mathrm{dL} .{ }^{87}$

The Trial to Reduce Cardiovascular Events with Aranesp Therapy (TREAT) is an ongoing randomized, double-blind, multicenter trial designed to determine the impact of anemia therapy on mortality and CVD in patients with CKD and type 2 diabetes. The trial enrolled aover 4000 patients, randomized to achieve target hemoglobin of $13 \mathrm{~g} / \mathrm{dL}$ or $\geq 9 \mathrm{~g} / \mathrm{dL}$ with DA therapy. Placebo was being given as "salvage" therapy for a hemoglobin of $<9 \mathrm{~g} / \mathrm{dL}$ in the low-hemoglobin group. The primary outcome is a composite endpoint of death, myocardial infarction, acute myocardial ischemia, $\mathrm{CHF}$, and stroke. The TREAT trial may provide critical guidance for the future management of anemia in this high cardiovascular-risk 
population and the impact of hemoglobin on development of HF and its outcomes. ${ }^{88}$

What might the mechanisms be for any salutary effect of erythropoietin in HF over and above increasing hemoglobin? The potentially beneficial effects of EPO in HF include reduced apoptosis of myocytes, reduced cardiac fibrosis, and reduced secretion of inflammatory mediators, a positive anti-oxidant effect, and neovascularization. The last-named effect has been demonstrated in a rat model of myocardial infarction. ${ }^{89}$

During EPO therapy it is important to avoid iron deficiency. Three studies, 2 uncontrolled ${ }^{90,91}$ and 1 double-blind, placebo-controlled study ${ }^{92}$ have shown improved hemoglobin, LVEF, NYHA class, LVH and dilation, reduced heart rate and pulmonary artery pressure with iron treatment alone. In addition, they demonstrated improved quality of life, exercise capacity, renal function, BNP, CRP and hospitalization. The higher the dose of intravenous iron given the greater was the hemoglobin response. These studies suggest that iron deficiency may also play a key role in the anemia of HF. Large controlled studies on this subject are currently in progress.

\section{Is there an optimal hemoglobin level?}

The only peer-reviewed HF recommendations that refer to anemia in HF, as outlined by the Canadian cardiovascular society in 2007, suggests treating any correctable causes of anemia (iron, vitamin B12, folate). It also states that currently there are insufficient data on routine use of ESA in the treatment of anemia and HF. However, blood transfusions and/or ESAs may be considered if the hemoglobin is less than $9 \mathrm{~g} / \mathrm{dL}$ and after correction of known factors (iron deficiency, vitamin B12, folate) for symptomatic HF. ${ }^{93}$ In routine practice, the answer to this question is mostly expert opinion based, with many cardiologists advocating a transfusion threshold to maintain an Hct of $\geq 30 \%$. This recommendation has been chiefly espoused by Herbert et al who noted that, in elderly patients suffering from acute myocardial infarction and angina, who presented on admission a Hct $<30 \%$, had better survival outcomes at 30 days if they were transfused. ${ }^{94}$ On the other hand, blood transfusion in the setting of acute coronary syndromes was associated with higher mortality, and this relationship persisted after adjustment for other predictive factors and timing of events in a retrospective cohort analysis of prospectively collected clinical trial data. ${ }^{95}$ In this study, the median baseline and nadir Hct measurements for patients who received a transfusion were $39.9 \%$ and $29.0 \%$, respectively, and for patients who did not receive blood, the values were $41.7 \%$ and $37.6 \%$, respectively. ${ }^{95}$
In the Normal Hematocrit Treatment trial, Besarab et al randomly assigned 1233 hemodialysis patients to Hct targets of either $30 \%$ or $42 \%$. Unfortunately, the trial was prematurely stopped for a statistically significant excess of vascular access thrombosis, with a non-significant increase in primary end points, namely non-fatal myocardial infarctions and death in the $42 \%$ Hct group. ${ }^{96}$ Later came the Open Label Correction of Hemoglobin and Outcomes in Renal Insufficiency (CHOIR) study, which randomly assigned 1432 CKD patients to either hemoglobin targets of $11.3 \mathrm{~g} / \mathrm{dL}$ or higher values of $13.5 \mathrm{~g} / \mathrm{dL}$. There was a significantly higher rate of primary outcome events, namely myocardial infarction, stroke, HF hospitalization and death in the normal hemoglobin group. ${ }^{97}$ Paradoxically a subsequent analysis indicated that it was not just the hemoglobin per se, but the inability to respond to increasing doses of EPO that predicted worse outcomes. ${ }^{98}$ Individuals administered progressively larger doses of ESA and those who could not attain the targeted hemoglobin of 13.3 were the ones at risk for morbidity and mortality. Our take home lesson should be that ESA resistance should not be treated with increases in ESA alone.

\section{Conclusion}

Anemia in the setting of HF is debilitating, fraught with severe morbidity and mortality in an ever-aging population. Many studies have highlighted the ominous implications of leaving this problem unresolved. Just as internists are recognizing the benefits in improving mortality and morbidity in early CKD referral, internists and cardiologists should be educated to recognize the hallmark of anemia as its management may make a difference in HF outcomes. This underpins the need for better system based practices that need to evolve beyond pharmacological methods tackling HF and should include anemia management.

None of the HF clinical practice guidelines from the US or Europe currently discuss the assessment and management of anemia in HF. Given current evidence, the use of ESA and supplemental iron should only be considered in patients with concomitant $\mathrm{CKD}$ or in the management of anemia (hemoglobin $<9 \mathrm{~g} / \mathrm{dL}$ ) with severe symptomatic heart failure, after iron, vitamin B12 and folate replacement. The National Kidney Foundation $\mathrm{KDOQI}^{\mathrm{TM}}$ clinical practice guideline were updated in 2007 after publication of the CREATE and CHOIR trials and recommended the use of ESA to achieve a hemoglobin target in the range of only 11.0 to $12.0 \mathrm{~g} / \mathrm{dL} .{ }^{99}$ With the removal of the quality of life claim by the Food and Drug Administration, the only claim for the use of ESA is to improve quality of life measures such as exercise tolerance 
and functional ability of CKD patients. ${ }^{100}$ In HF patients, even these quality of life measures have not been convincingly shown to improve. Therefore, until data from long-term clinical studies are available for HF patients with anemia, the use of ESA is not recommended in anemic patients with HF who do not have a CKD indication for its use.

Anemia is a common co-morbidity in patients with HF and is associated with worse long-term outcomes. Although the cause of anemia in HF is unclear, the weight of evidence suggests that renal dysfunction and neurohormonal and proinflammatory cytokine activation in HF favor the development of anemia. Similarly, the mechanisms by which anemia worsens HF outcomes are unknown but may be related to increased myocardial workload. Although anemia is a rational therapeutic target to improve outcomes, there are as yet no convincing data on the efficacy and long-term safety of ESA. Further studies are required to understand the basis of the remarkable association of anemia with HF outcomes, to assess prospectively the potential benefit of correcting anemia, to evaluate the ideal threshold at which therapy should be initiated, and the extent of correction considered safe and desirable. Two large mortality morbidity trials, TREAT in $\mathrm{CKD}^{88}$ and RED-HF in HF, are in progress and may be able to provide answers to some of these questions. ${ }^{87}$

\section{Disclosures}

Anatole Besarab: consultant to Amgen, Affymax, Roche, Fibrogen (all manufucaturers of ESAs) and is on speakers' board and has received honoraria from Watson Pharma and Amereican Regent Labs.

Michael Hudson: grant support to the Henry Ford Coordinating Center from Scios/Johnson \& Johnson, Schering Plough, and deCode Genetics.

\section{References}

1. O'Connell JB, Bristow MR. Economic impact of heart failure in the United States: time for a different approach. J Heart Lung Transplant. 1994;13(4):S107-S112.

2. Smith GL, Lichtman JH, Bracken MB, et al. Renal impairment and outcomes in heart failure: systematic review and meta-analysis. $\mathrm{J} \mathrm{Am}$ Coll Cardiol. 2006;47(10):1987-1996.

3. Silverberg DS, Wexler D, Blum M, et al. The use of subcutaneous erythropoietin and intravenous iron for the treatment of the anemia of severe, resistant congestive heart failure improves cardiac and renal function and functional cardiac class, and markedly reduces hospitalizations. J Am Coll Cardiol. 2000;35(7):1737-1744.

4. Androne AS, Katz SD, Lund L, et al. Hemodilution is common in patients with advanced heart failure. Circulation. 2003;107(2): 226-229.

5. Mozaffarian D, Nye R, Levy WC. Anemia predicts mortality in severe heart failure: the prospective randomized amlodipine survival evaluation (PRAISE). J Am Coll Cardiol. 2003;41(11):1933-1939.
6. McClellan WM, Flanders WD, Langston RD, Jurkovitz C, Presley R. Anemia and renal insufficiency are independent risk factors for death among patients with congestive heart failure admitted to community hospitals: a population-based study. J Am Soc Nephrol. 2002;13(7): 1928-1936.

7. Tanner H, Moschovitis G, Kuster GM, et al. The prevalence of anemia in chronic heart failure. Int J Cardiol. 2002;86(1):115-121.

8. Anand IS, Kuskowski MA, Rector TS, et al. Anemia and change in hemoglobin over time related to mortality and morbidity in patients with chronic heart failure: results from Val-HeFT. Circulation. 2005;112(8):1121-1127.

9. Hillege HL, Girbes AR, de Kam PJ, et al. Renal function, neurohormonal activation, and survival in patients with chronic heart failure. Circulation. 2000;102(2):203-210.

10. Miller LW, Missov ED. Epidemiology of heart failure. Cardiol Clin. 2001;19(4):547-555.

11. Cleland JG, Khand A, Clark A. The heart failure epidemic: exactly how big is it? Eur Heart J. 2001;22(8):623-626.

12. Rose EA, Gelijns AC, Moskowitz AJ, et al. Long-term mechanical left ventricular assistance for end-stage heart failure. $N \mathrm{Engl} \mathrm{J} \mathrm{Med}$. 2001;345(20):1435-1443.

13. Nanas JN, Matsouka C, Karageorgopoulos D, et al. Etiology of anemia in patients with advanced heart failure. $\mathrm{J} \mathrm{Am} \mathrm{Coll} \mathrm{Cardiol.}$ 2006;48(12):2485-2489.

14. Aronow WS. Epidemiology, pathophysiology, prognosis, and treatment of systolic and diastolic heart failure. Cardiol Rev. 2006;14(3):108-124.

15. Aronow WS, Ahn C, Kronzon I, Koenigsberg M. Congestive heart failure, coronary events and atherothrombotic brain infarction in elderly blacks and whites with systemic hypertension and with and without echocardiographic and electrocardiographic evidence of left ventricular hypertrophy. Am J Cardiol. 1991;67(4):295-299.

16. Aronow WS, Ahn C, Kronzon I. Comparison of incidences of congestive heart failure in older African-Americans, Hispanics, and whites. Am J Cardiol. 1999;84(5):611-612.

17. McClellan WM, Langston RD, Presley R. Medicare patients with cardiovascular disease have a high prevalence of chronic kidney disease and a high rate of progression to end-stage renal disease. J Am Soc Nephrol. 2004;15(7):1912-1919.

18. Collins AJ, Foley R, Herzog C, et al. Excerpts from the United States Renal Data System 2007 annual data report. Am J Kidney Dis. 2008; 51(1 Suppl 1):S1-S320.

19. Foley RN, Murray AM, Li S, et al. Chronic kidney disease and the risk for cardiovascular disease, renal replacement, and death in the United States Medicare population, 1998 to 1999. J Am Soc Nephrol. 2005;16(2):489-495.

20. Berry C, Hogg K, Norrie J, Stevenson K, Brett M, McMurray J. Heart failure with preserved left ventricular systolic function: a hospital cohort study. Heart. 2005;91(7):907-913.

21. Klapholz M, Maurer M, Lowe AM, et al. Hospitalization for heart failure in the presence of a normal left ventricular ejection fraction: results of the New York Heart Failure Registry. J Am Coll Cardiol. 2004;43(8):1432-1438.

22. Brucks S, Little WC, Chao T, et al. Relation of anemia to diastolic heart failure and the effect on outcome. Am J Cardiol. 2004;93(8): 1055-1057.

23. Collins AJ. The hemoglobin link to adverse outcomes. Adv Stud Med. 2003;3(3C):S194-S197.

24. Silva RP, Barbosa PH, Kimura OS, et al. Prevalance of anemia and its association with cardio-renal syndrome. Int J Cardiol. 2007;120(2): 232-236.

25. Ronco C, Haapio M, House AA, Anavekar N, Bellomo R. Cardiorenal syndrome. J Am Coll Cardiol. 2008;52(19):1527-1539.

26. Ronco C, House AA, Haapio M. Cardiorenal syndrome: refining the definition of a complex symbiosis gone wrong. Intensive Care Med. 2008;34(5):957-962. 
27. Ronco C, House AA, Haapio M. Cardiorenal and renocardiac syndromes: the need for a comprehensive classification and consensus. Nat Clin Pract Nephrol. 2008;4(6):310-311.

28. Silverberg DS, D W, A I. The Cardio Renal Anemia (CRA Syndrome: Congestive heart failure, Chronic Kidney Insufficiency, and Anemia. Dialysis Times. 2004;10(1):1-8.

29. Silverberg DS, Wexler D, Blum M, et al. Effect of correction of anemia with erythropoietin and intravenous iron in resistant heart failure in octogenarians. Isr Med Assoc J. 2003;5(5):337-339.

30. Johnson DW, Craven AM, Isbel NM. Modification of cardiovascular risk in hemodialysis patients: an evidence-based review. Hemodial Int. 2007;11(1):1-14.

31. Collins AJ, Li S, Ma JZ, Herzog C. Cardiovascular disease in endstage renal disease patients. Am J Kidney Dis. 2001;38(4 Suppl 1): S26-S29.

32. Fried LF, Shlipak MG, Crump C, et al. Renal insufficiency as a predictor of cardiovascular outcomes and mortality in elderly individuals. $\mathrm{J} \mathrm{Am}$ Coll Cardiol. 2003;41(8):1364-1372.

33. Sarnak MJ, Levey AS. Cardiovascular disease and chronic renal disease: a new paradigm. Am J Kidney Dis. 2000;35(4 Suppl 1):S117-S131.

34. Foley RN, Parfrey PS, Harnett JD, et al. Clinical and echocardiographic disease in patients starting end-stage renal disease therapy. Kidney Int. 1995;47(1):186-192.

35. Foley RN, Parfrey PS, Harnett JD, Kent GM, Murray DC, Barre PE. The impact of anemia on cardiomyopathy, morbidity, and and mortality in end-stage renal disease. Am J Kidney Dis. 1996;28(1):53-61.

36. Harnett JD, Foley RN, Kent GM, Barre PE, Murray D, Parfrey PS. Congestive heart failure in dialysis patients: prevalence, incidence, prognosis and risk factors. Kidney Int. 1995;47(3):884-890.

37. Nutritional Anaemias:Report of a WHO Scientific Group: World Health Organization; 1968.

38. Kazmi WH, Kausz AT, Khan S, et al. Anemia: an early complication of chronic renal insufficiency. Am J Kidney Dis. 2001;38(4) 803-812

39. Levin A. Prevalence of cardiovascular damage in early renal disease. Nephrol Dial Transplant. 2001;16 Suppl 2:S7-S11.

40. Levin A, Singer J, Thompson CR, Ross H, Lewis M. Prevalent left ventricular hypertrophy in the predialysis population: identifying opportunities for intervention. Am J Kidney Dis. 1996;27(3) 347-354.

41. Levin A, Thompson CR, Ethier J, et al. Left ventricular mass index increase in early renal disease: impact of decline in hemoglobin. Am J Kidney Dis. 1999;34(1):125-134.

42. Collins AJ, Li S, Gilbertson DT, Liu J, Chen SC, Herzog CA. Chronic kidney disease and cardiovascular disease in the Medicare population. Kidney Int Suppl. 2003(87):S24-S31.

43. Tong EM, Nissenson AR. Erythropoietin and anemia. Semin Nephrol. 2001;21(2):190-203

44. Vaziri ND. Erythropoietin and transferrin metabolism in nephrotic syndrome. Am J Kidney Dis. 2001;38(1):1-8.

45. Genth-Zotz S, Bolger AP, Anker SD. Tumor necrosis factor alpha in chronic heart failure. Clinical manifestation and therapeutic possibilities. Herz. 2001;26(7):437-446.

46. Torre-Amione G, Kapadia S, Benedict C, Oral H, Young JB, Mann DL. Proinflammatory cytokine levels in patients with depressed left ventricular ejection fraction: a report from the Studies of Left Ventricular Dysfunction (SOLVD). J Am Coll Cardiol. 1996;27(5):1201-1206.

47. Johnson RA, Waddelow TA, Caro J, Oliff A, Roodman GD. Chronic exposure to tumor necrosis factor in vivo preferentially inhibits erythropoiesis in nude mice. Blood. 1989;74(1):130-138.

48. Iversen PO, Woldbaek PR, Tonnessen T, Christensen G. Decreased hematopoiesis in bone marrow of mice with congestive heart failure. Am J Physiol Regul Integr Comp Physiol. 2002;282(1):R16-R172.

49. Tang YD, Katz SD. Anemia in chronic heart failure: prevalence, etiology, clinical correlates, and treatment options. Circulation. 2006;113(20):2454-2461.
50. Effect of enalapril on mortality and the development of heart failure in asymptomatic patients with reduced left ventricular ejection fractions. The SOLVD Investigattors. N Engl J Med. 1992;327(10):685-691.

51. Le Meur Y, Lorgeot V, Comte L, et al. Plasma levels and metabolism of AcSDKP in patients with chronic renal failure: relationship with erythropoietin requirements. Am J Kidney Dis. 2001;38(3):510-517.

52. Volpe M, Tritto C, Testa U, et al. Blood levels of erythropoietin in congestive heart failure and correlation with clinical, hemodynamic, and hormonal profiles. Am J Cardiol. 1994;74(5):468-473.

53. van der Meer P, Voors AA, Lipsic E, Smilde TD, van Gilst WH, van Veldhuisen DJ. Prognostic value of plasma erythropoietin on mortality in patients with chronic heart failure. $\mathrm{J} \mathrm{Am} \mathrm{Coll} \mathrm{Cardiol.}$ 2004;44(1):63-67.

54. Radtke HW, Claussner A, Erbes PM, Scheuermann EH, Schoeppe W, Koch KM. Serum erythropoietin concentration in chronic renal failure: relationship to degree of anemia and excretory renal function. Blood. 1979;54(4):877-884.

55. Schrier RW. Cardiorenal versus renocardiac syndrome: is there a difference? Nat Clin Pract Nephrol. 2007 Dec;3(12):637.

56. Abraham WT, Adams KF, Fonarow GC, et al. In-hospital mortality in patients with acute decompensated heart failure requiring intravenous vasoactive medications: an analysis from the Acute Decompensated Heart Failure National Registry (ADHERE). J Am Coll Cardiol. 2005;46(1):5764.

57. Fonarow GC. The Acute Decompensated Heart Failure National Registry (ADHERE): opportunities to improve care of patients hospitalized with acute decompensated heart failure. Rev Cardiovasc Med. 2003; 4 Suppl 7:S21-S30.

58. Aronson D, Mittleman MA, Burger AJ. Elevated blood urea nitrogen level as a predictor of mortality in patients admitted for decompensated heart failure. Am J Med. 2004;116(7):466-473.

59. Filippatos G, Rossi J, Lloyd-Jones DM, et al. Prognostic value of blood urea nitrogen in patients hospitalized with worsening heart failure: insights from the Acute and Chronic Therapeutic Impact of a Vasopressin Antagonist in Chronic Heart Failure (ACTIV in CHF) study. J Card Fail. 2007;13(5):360-364.

60. Dries DL, Exner DV, Domanski MJ, Greenberg B, Stevenson LW. The prognostic implications of renal insufficiency in asymptomatic and symptomatic patients with left ventricular systolic dysfunction. $J \mathrm{Am}$ Coll Cardiol. 2000;35(3):681-689.

61. Gottlieb SS, Abraham W, Butler J, et al. The prognostic importance of different definitions of worsening renal function in congestive heart failure. J Card Fail. 2002;8(3):136-141.

62. Kannel WB. Epidemiology and prevention of cardiac failure: Framingham Study insights. Eur Heart J. 1987;8 Suppl:F23-F26.

63. Silverberg DS, Wexler D, Sheps D, et al. The effect of correction of mild anemia in severe, resistant congestive heart failure using subcutaneous erythropoietin and intravenous iron: a randomized controlled study. J Am Coll Cardiol. 2001;37(7):1775-1780.

64. Horwich TB, Fonarow GC, Hamilton MA, MacLellan WR, Borenstein J. Anemia is associated with worse symptoms, greater impairment in functional capacity and a significant increase in mortality in patients with advanced heart failure. J Am Coll Cardiol. 2002;39(11): 1780-1786.

65. McAlister FA, Ezekowitz J, Tonelli M, Armstrong PW. Renal insufficiency and heart failure: prognostic and therapeutic implications from a prospective cohort study. Circulation. 2004;109(8):1004-1009.

66. Alexander M, Grumbach K, Remy L, Rowell R, Massie BM. Congestive heart failure hospitalizations and survival in California: patterns according to race/ethnicity. Am Heart J. 1999;137(5):919-927.

67. Silverberg DS, Wexler D, Iaina A. The role of anemia in the progression of congestive heart failure. Is there a place for erythropoietin and intravenous iron? J Nephrol. 2004;17(6):749-761.

68. Kosiborod M, Smith GL, Radford MJ, Foody JM, Krumholz HM. The prognostic importance of anemia in patients with heart failure. Am J Med. 2003;114(2):112-119. 
69. Ezekowitz JA, McAlister FA, Armstrong PW. Anemia is common in heart failure and is associated with poor outcomes: insights from a cohort of 12065 patients with new-onset heart failure. Circulation. 2003;107(2):223-225.

70. Al-Ahmad A, Rand WM, Manjunath G, et al. Reduced kidney function and anemia as risk factors for mortality in patients with left ventricular dysfunction. J Am Coll Cardiol. 2001;38(4):955-962.

71. Felker GM, Leimberger JD, Califf RM, et al. Risk stratification after hospitalization for decompensated heart failure. J Card Fail. 2004;10(6):460-466.

72. Szachniewicz J, Petruk-Kowalczyk J, Majda J, et al. Anaemia is an independent predictor of poor outcome in patients with chronic heart failure. Int J Cardiol. 2003;90(2-3):303-308.

73. Groenveld HF, Januzzi JL, Damman K, et al. Anemia and mortality in heart failure patients: a systematic review and meta-analysis. $\mathrm{J} \mathrm{Am}$ Coll Cardiol. 2008;52(10):818.

74. Kalra PR, Bolger AP, Francis DP, et al. Effect of anemia on exercise tolerance in chronic heart failure in men. Am J Cardiol. 2003;91(7):888-891.

75. Herzog CA, Muster HA, Li S, Collins AJ. Impact of congestive heart failure, chronic kidney disease, and anemia on survival in the Medicare population. J Card Fail. 2004;10(6):467-472.

76. Silverberg DS, Iaina A, Wexler D, Blum M. The pathological consequences of anaemia. Clin Lab Haematol. 2001;23(1):1-6.

77. Silverberg DS, Wexler D, Blum M, et al. The effect of correction of anaemia in diabetics and non-diabetics with severe resistant congestive heart failure and chronic renal failure by subcutaneous erythropoietin and intravenous iron. Nephrol Dial Transplant. 2003;18(1):141-146.

78. Vaisman N, Silverberg DS, Wexler D, et al. Correction of anemia in patients with congestive heart failure increases resting energy expenditure. Clin Nutr. 2004;23(3):355-361.

79. Silverberg DS, Wexler D, Blum M, et al. Effects of treatment with epoetin beta on outcomes in patients with anaemia and chronic heart failure. Kidney Blood Press Res. 2005;28(1):41-47.

80. Zilberman M, Silverberg DS, Bits I, et al. Improvement of anemia with erythropoietin and intravenous iron reduces sleep-related breathing disorders and improves daytime sleepiness in anemic patients with congestive heart failure. Am Heart J. 2007;154(5):870-876.

81. Silverberg DS, Wexler D, Blum M, et al. Aggressive therapy of congestive heart failure and associated chronic renal failure with medications and correction of anemia stops or slows the progression of both diseases. Perit Dial Int. 2001;21 Supp1 3:S236-S240.

82. Mancini DM, Katz SD, Lang CC, LaManca J, Hudaihed A, Androne AS. Effect of erythropoietin on exercise capacity in patients with moderate to severe chronic heart failure. Circulation. 2003;107(2):294-299.

83. Van der Meer P, Groenveld H, Januzzi JL, Van Veldhuisen DJ. Erythropoietin Treatment in Patients with Chronic Heart Failure: a meta-analysis. Heart. 2009.

84. Silverberg DS, Wexler D, Iaina A, Schwartz D. The role of correction of anaemia in patients with congestive heart failure: a short review. Eur J Heart Fail. 2008;10(9):819-823.

85. Ghali JK, Anand IS, Abraham WT, et al. Randomized double-blind trial of darbepoetin alfa in patients with symptomatic heart failure and anemia. Circulation. 2008;117(4):526-535.

86. van Veldhuisen DJ, Dickstein K, Cohen-Solal A, et al. Randomized, double-blind, placebo-controlled study to evaluate the effect of two dosing regimens of darbepoetin alfa in patients with heart failure and anaemia. Eur Heart J. 2007;28(18):2208-2216.

Vascular Health and Risk Management

\section{Publish your work in this journal}

Vascular Health and Risk Management is an international, peerreviewed journal of therapeutics and risk management, focusing on concise rapid reporting of clinical studies on the processes involved in the maintenance of vascular health; the monitoring, prevention and treatment of vascular disease and its sequelae; and the involvement of
87. van Veldhuisen DJ, McMurray JJ. Are erythropoietin stimulating proteins safe and efficacious in heart failure? Why we need an adequately powered randomised outcome trial. Eur J Heart Fail. 2007;9(2):110-112.

88. Mix TC, Brenner RM, Cooper ME, et al. Rationale - Trial to Reduce Cardiovascular Events with Aranesp Therapy (TREAT): evolving the management of cardiovascular risk in patients with chronic kidney disease. Am Heart J. 2005;149(3):408-413.

89. van der Meer P, Lipsic E, Henning RH, et al. Erythropoietin induces neovascularization and improves cardiac function in rats with heart failure after myocardial infarction. J Am Coll Cardiol. 2005;46(1): 125-133.

90. Bolger AP, Bartlett FR, Penston HS, et al. Intravenous iron alone for the treatment of anemia in patients with chronic heart failure. $\mathrm{J} \mathrm{Am}$ Coll Cardiol. 2006;48(6):1225-1227.

91. Usmanov RI, Zueva EB, Silverberg DS, Shaked M. Intravenous iron without erythropoietin for the treatment of iron deficiency anemia in patients with moderate to severe congestive heart failure and chronic kidney insufficiency. J Nephrol. 2008;21(2):236-242.

92. Toblli JE, Lombrana A, Duarte P, Di Gennaro F. Intravenous iron reduces NT-pro-brain natriuretic peptide in anemic patients with chronic heart failure and renal insufficiency. J Am Coll Cardiol. 2007;50(17): 1657-1665.

93. Arnold JM, Howlett JG, Dorian P, et al. Canadian Cardiovascular Society Consensus Conference recommendations on heart failure update 2007: Prevention, management during intercurrent illness or acute decompensation, and use of biomarkers. Can J Cardiol. 2007;23(1):21-45

94. Hebert PC, Wells G, Blajchman MA, et al. A multicenter, randomized, controlled clinical trial of transfusion requirements in critical care. Transfusion Requirements in Critical Care Investigators, Canadian Critical Care Trials Group. N Engl J Med. 1999;340(6):409-417.

95. Rao SV, Jollis JG, Harrington RA, et al. Relationship of blood transfusion and clinical outcomes in patients with acute coronary syndromes. JAMA. 2004;292:1555-1562.

96. Besarab A, Bolton WK, Browne JK, et al. The effects of normal as compared with low hematocrit values in patients with cardiac disease who are receiving hemodialysis and epoetin. $N$ Engl J Med. 1998;339(9):584-590.

97. Singh AK, Szczech L, Tang KL, et al. Correction of anemia with epoetin alfa in chronic kidney disease. $N$ Engl J Med. 2006;355(20):2085-2098.

98. Szczech LA, Barnhart HX, Inrig JK, et al. Secondary analysis of the CHOIR trial epoetin-alpha dose and achieved hemoglobin outcomes. Kidney Int. 2008;74(6):791-798.

99. KDOQI Clinical Practice Guideline and Clinical Practice Recommendations for anemia in chronic kidney disease: 2007 update of hemoglobin target. Am J Kidney Dis. 2007;50(3):471-530.

100. Anand IS. Anemia and chronic heart failure implications and treatment options. J Am Coll Cardiol. 2008;52(7):501-511.

101. Anand IS, ChandrashekharY, Ferrari R, Poole-Wilson PA, Harris PC. Pathogenesis of oedema in chronic severe anaemia: studies of body water and sodium, renal function, haemodynamic variables, and plasma hormones. Br Heart J. 1993;70(4):357-362.

metabolic disorders, particularly diabetes. This journal is indexed on PubMed Central and MedLine. The manuscript management system is completely online and includes a very quick and fair peer-review system, which is all easy to use. Visit http://www.dovepress.com/ testimonials.php to read real quotes from published authors. 